\title{
Chronic Kidney Disease in Primary Care: An Opportunity for Generalists
}

\author{
Delphine S. Tuot, $M D, C M^{\top}$ and Neil R. Powe, $M D^{2}$ \\ 'Division of Nephrology, San Francisco General Hospital, University of California San Francisco, San Francisco, CA, USA; ${ }^{2}$ Department of \\ Medicine, San Francisco General Hospital, University of California San Francisco, San Francisco, CA, USA.
}

$\mathrm{J}$ Gen Intern Med 26(4):356-8

DOI: $10.1007 / \mathrm{s} 11606-011-1650-8$

(c) The Author(s) 2011. This article is published with open access at Springerlink.com

$\mathrm{C}$ hronic kidney disease (CKD) is a public health concern affecting nearly 26 million Americans. ${ }^{1}$ However, unlike other chronic conditions with a similarly large prevalence in the US (e.g., hypertension, diabetes mellitus, and chronic obstructive pulmonary disease) and despite the association between CKD and morbidity and mortality, CKD has been largely under-recognized and not aggressively treated by primary care providers (PCP). ${ }^{2,3}$ In a landmark paper in 2004, Go et al. demonstrated a strong graded association between worsening kidney function and risk of hospitalizations, cardiovascular events, and death. ${ }^{4}$ More recent studies have corroborated these findings ${ }^{5}$ and also linked CKD to increased rates of disability, ${ }^{6,7}$ poorer quality of life, ${ }^{6}$ greater cognitive decline, ${ }^{8}$ and an increased number of infections. ${ }^{9}$ Importantly, there is now strong evidence that medical therapies can alter the course of disease. ${ }^{10}$ Providers can slow progression of CKD to end-stage renal disease (ESRD) with good blood pressure control (particularly among those with macroalbuminuria), ${ }^{11}$ tighter glycemic control, ${ }^{12}$ decreased albuminuria through the use of angiotensin converting enzyme inhibitors (ACEI) or angiotensin receptor blockers (ARB) ${ }^{13}$ and by limiting the use of nephrotoxic medications such as non-steroidal anti-inflammatory agents. ${ }^{14}$ Emerging therapies such as daily administration of oral sodium bicarbonate also show promise. ${ }^{15}$ Less strong evidence suggests that providers can also modify the high morality rate associated with $\mathrm{CKD}$ via similar mechanisms, including blood pressure control and use of ACEI/ARBs and HMG Co-A reductase inhibitors for cardiovascular risk reduction. ${ }^{13,16}$

Given the large problem at hand and the availability of good therapies to modify the disease course, the importance of CKD recognition and aggressive management at earlier stages cannot be underestimated. And given the undersupply of nephrologists in the US and paucity of referrals to them, ${ }^{17,18}$ PCPs represent the first line of CKD care. This includes screening patients at high risk of CKD, identifying CKD, and managing early stage disease, including its clinical manifestations, with nephrology assistance when appropriate.

In this issue of JGIM, Dalrymple et al. ${ }^{19}$ and Allen et al. ${ }^{20}$ highlight the importance of $\mathrm{CKD}$ care to modify health

Published online February 26, 2011 outcomes and provide some insight into PCP management of CKD. Using the Cardiovascular Health Study, Dalrymple and colleagues compare the overall risk and risk factors of ESRD, cardiovascular death, and non-cardiovascular death among older (mean age of 75 years) community-dwelling adults with moderate CKD [median estimated glomerular filtration rate (eGFR) of $53 \mathrm{ml} / \mathrm{min} / 1.73 \mathrm{~m}^{2}$ ]. They corroborate previous evidence that risk of death is much more likely than progression to ESRD in older adults ${ }^{21}$ and highlight risk factors associated with all-cause mortality. Modifiable risk factors include body mass index $<24.9$ and current tobacco smoking; non-modifiable but preventable risk factors include presence of hypertension and/or diabetes and prevalent heart failure and/or cardiovascular disease.

While their comparative risk model is limited by a lack of data about proteinuria, thus hampering their ability to discern individuals at the highest risk of ESRD, Dalrymple and colleagues do underscore the importance of identifying CKD in the elderly, as those with kidney disease benefit from more aggressive cardiovascular risk reduction than their non-CKD counterparts.

This conclusion cannot be overemphasized. Aggressive cardiovascular risk factor modification among CKD patients in the US is lacking. In Dalrymple et al.'s study population, self-reported use of ACEI/ARB, an evidence-based therapy to improve the cardiovascular risk profile (and simultaneously decrease the risk of ESRD), ranged from a mere $10 \%$ to $17 \%$. A similar dismal percentage has been noted previously in other adult populations. ${ }^{22}$ Studies have also demonstrated poor implementation of other components of $\mathrm{CKD}$ care in non-clinical database populations and research cohorts. Blood pressure is not often controlled, ${ }^{23}$ glycemic control is not routinely optimized, ${ }^{24}$ and chronic NSAID use is too frequent. ${ }^{25}$

Also in this issue, Allen and colleagues expand upon this theme by confirming the poor adoption of high-quality CKD care, including cardiovascular risk reduction, in a clinical setting. In their multi-specialty group practice caring for predominantly insured patients with moderate CKD (stage 3), nearly $90 \%$ of patients received yearly eGFR testing. Despite these ample opportunities for PCPs to identify and manage $\mathrm{CKD}$, only $30 \%$ received annual urine protein testing, limiting providers' chances to slow CKD progression by minimizing proteinuria. Indeed, only $75 \%$ of patients received ACEI/ARB therapy, and 54\% achieved guideline-concordant blood pressure control, the main therapies that can lead to proteinuria reduction. Cardiovascular risk reduction in their population was also suboptimal; nearly three-quarters of patients had annual lipid testing, but only $44 \%$ achieved an $\mathrm{LDL}<100 \mathrm{mg} / \mathrm{dl}$, the recommended target. Perhaps even more concerning, over $25 \%$ of patients were prescribed one or more inappropriate medications 
for their level of kidney dysfunction. Reassuringly, achievement of guideline-concordant CKD care was greater among individuals with higher risks of CKD-associated morbidity and mortality than among those with lower risk.

One important point deserves mention. The practice settings and patients studied by Allen et al. may not be representative of those in the US. Minorities represent a larger proportion of the US population than in this study, and they, as well as the poor, are at highest risk for ESRD. ${ }^{26}$ Therefore, the relative lack of sociodemographic patient diversity, leading to a paucity of high-risk CKD patients, may underestimate the provision of guidelineconcordant CKD care in the US. On the other hand, the affluence and enhanced multidisciplinary coordination of the health care system in Massachusetts and the very high percentage of insured patients likely overestimate the quality of care received by the average US resident with chronic kidney disease.

Despite these limitations, the study results highlight certain challenges that impede the adoption of high-quality CKD care by generalist physicians. Poor provider awareness of CKD and national CKD management guidelines, and poor communication among PCPs and nephrologists are two formidable challenges to overcome. Unsurprisingly, in this study, provider recognition of CKD was associated with greater monitoring of kidney disease and decreased prescription of inappropriate medications; nephrology involvement was associated with improved cardiovascular risk reduction and enhanced treatment of metabolic bone disease. Other barriers that impede the adoption of high-quality CKD care include the prevalence of higher profile co-morbid chronic illnesses such as diabetes and cardiovascular disease, national policies that emphasize acute care visits over ones that focus on care for chronic medical conditions, and a lack of funding opportunities for CKD implementation research. Additional challenges shown in other studies include lack of education of primary care physicians in the use of glomerular filtration rate estimating equations, poor patient-physician communication, and disagreement of generalists and specialists on their respective roles in CKD management. ${ }^{27-30}$

It is imperative for future CKD research to focus on the elimination of these barriers. More effective use of technology to help providers identify patients with $\mathrm{CKD}$ and provision of enhanced decision support systems to increase the quality of CKD care in the face of competing comorbid conditions, are essential to move the field forward. Health care delivery systems that allow for greater communication between internists and pharmacists and co-management involving internists and nephrologists are key to provide targeted, coordinated, cost-effective care. The creation of sustainable patient self-management support programs that incorporate and build upon the patient education tools created by the National Kidney Disease Education Program and others, including the National Kidney Foundation, is necessary to raise general awareness of kidney disease and its complications and encourage life-style modifications to improve CKD risk profiles. Finally, a system of national surveillance for CKD, now underway, is essential to track the nation's progress in improving CKD care. $^{31}$

The publication of these two articles underscores the importance of primary care providers in the care of patients with CKD. The opportunity to further engage generalists, educators, and researchers is now. It is time to design and implement interventions that increase recognition of $\mathrm{CKD}$, facilitate delivery of high- quality, coordinated CKD care, and improve health outcomes for the growing number of patients affected by the CKD epidemic. Primary care physicians can rise to this challenge.

Grant Support: Dr. Tuot is supported by an American Kidney Fund Clinical Scientist. Grant. Dr. Powe is supported by grant K24DK02643 from the National Institute of Diabetes and Digestive and Kidney Diseases, Bethesda, MD.

Open Access: This article is distributed under the terms of the Creative Commons Attribution Noncommercial License which permits any noncommercial use, distribution, and reproduction in any medium, provided the original author(s) and source are credited.

Corresponding Author: Neil R. Powe, MD; Department of Medicine, San Francisco General Hospital, University of California San Francisco, 1001 Potrero Ave, 5F38, San Francisco, CA 94110, USA (e-mail: npowe@medsfgh.ucsf.edu).

\section{REFERENCES}

1. Coresh J, Selvin E, Stevens LA, et al. Prevalence of chronic kidney disease in the United States. JAMA. 2007;298(17):2038-47.

2. Boulware LE, Troll MU, Jaar BG, Myers DI, Powe NR. Identification and referral of patients with progressive CKD: a national study. Am J Kidney Dis. 2006;48(2): 192-204.

3. Guessous I, McClellan W, Vupputuri S, Wasse H. Low documentation of chronic kidney disease among high-risk patients in a managed care population: a retrospective cohort study. BMC Nephrol. 2009;10(1):25.

4. Go AS, Chertow GM, Fan D, McCulloch CE, Hsu CY. Chronic kidney disease and the risks of death, cardiovascular events, and hospitalization. N Engl J Med. 2004;351(13):1296-305.

5. Tonelli M, Wiebe N, Culleton B, et al. Chronic kidney disease and mortality risk: a systematic review. J Am Soc Nephrol. 2006;17(7):2034-47.

6. Gorodetskaya I, Zenios S, McCulloch CE, et al. Health-related quality of life and estimates of utility in chronic kidney disease. Kidney Int. 2005;68(6):2801-8.

7. Plantinga LC, Johansen $\mathbf{K}$, Crews DC, et al. Association of CKD With Disability in the United States. Am J Kidney Dis. 2011;57(2):212-7.

8. Kurella Tamura M, Wadley $\mathbf{V}$, Yaffe $\mathbf{K}$, et al. Kidney function and cognitive impairment in US adults: the Reasons for Geographic and Racial Differences in Stroke (REGARDS) Study. Am J Kidney Dis. 2008;52(2):227-34.

9. James MT, Quan $\mathbf{H}$, Tonelli $\mathbf{M}$, et al. CKD and risk of hospitalization and death with pneumonia. Am J Kidney Dis. 2009;54(1):24-32.

10. Sarnak MJ, Levey AS, Schoolwerth AC, et al. Kidney disease as a risk factor for development of cardiovascular disease: a statement from the American Heart Association Councils on Kidney in Cardiovascular Disease, High Blood Pressure Research, Clinical Cardiology, and Epidemiology and Prevention. Hypertension. 2003;42(5):1050-65.

11. Sarnak MJ, Greene T, Wang X, et al. The effect of a lower target blood pressure on the progression of kidney disease: long-term follow-up of the modification of diet in renal disease study. Ann Intern Med. 2005;142 (5):342-51.

12. Patel A, MacMahon S, Chalmers $\mathbf{J}$, et al. Intensive blood glucose control and vascular outcomes in patients with type 2 diabetes. N Engl J Med. 2008;358(24):2560-72.

13. Patel A, MacMahon S, Chalmers J, et al. Effects of a fixed combination of perindopril and indapamide on macrovascular and microvascular outcomes in patients with type 2 diabetes mellitus (the ADVANCE trial): a randomised controlled trial. Lancet. 2007;370(9590):829-40.

14. Gooch K, Culleton BF, Manns BJ, et al. NSAID use and progression of chronic kidney disease. Am J Med. 2007;120(3):280 el-7.

15. Mahajan A, Simoni J, Sheather SJ, Broglio KR, Rajab MH, Wesson DE. Daily oral sodium bicarbonate preserves glomerular filtration rate by slowing its decline in early hypertensive nephropathy. Kidney Int. 78(3):303-9.

16. Navaneethan SD, Pansini F, Perkovic V, et al. HMG CoA reductase inhibitors (statins) for people with chronic kidney disease not requiring dialysis. Cochrane Database Syst Rev. 2009(2):CD007784.

17. Martinez-Ramirez HR, Jalomo-Martinez B, Cortes-Sanabria L, et al. Renal function preservation in type 2 diabetes mellitus patients with early 
nephropathy: a comparative prospective cohort study between primary health care doctors and a nephrologist. Am J Kidney Dis. 2006;47(1):78-87.

18. Kinchen KS, Sadler J, Fink N, et al. The timing of specialist evaluation in chronic kidney disease and mortality. Ann Intern Med. 2002;137 (6):479-86.

19. Dalrymple LS, Katz R, Kestenbaum B, et al. Chronic kidney disease and the risk of end-stage renal disease versus death. J Gen Intern Med. doi:10.1007/s11606-010-1511-x

20. Allen AS, Forman JP, Orav EJ, Bates DW, Denker BM, Sequist TD. Primary care management of chronic kidney disease. J Gen Intern Med. doi: $10.1007 / \mathrm{s} 11606-010-1523-6$

21. O'Hare AM, Choi AI, Bertenthal D, et al. Age affects outcomes in chronic kidney disease. J Am Soc Nephrol. 2007;18(10):2758-65.0

22. Peralta CA, Hicks LS, Chertow GM, et al. Control of hypertension in adults with chronic kidney disease in the United States. Hypertension. 2005;45(6): 1119-24.

23. Plantinga LC, Miller ER, 3rd, Stevens LA, et al. Blood pressure control among persons without and with chronic kidney disease: US trends and risk factors 1999-2006. Hypertension. 2009;54(1):47-56.

24. Tuot DS, Plantinga L, Hsu C-y, Powe NR. Is awareness of chronic kidney disease associated with greater achievement of evidence-based medical therapies? J Am Soc Nephrol. 2010;21:132A.
25. Plantinga L, Grubbs V, Hsu C-y, et al. High non-steroidal antiinflammatory drug use among persons with chronic kidney disease in the U.S. J Am Soc Nephrol. 2010;21:665A.

26. Volkova N, McClellan W, Klein M, et al. Neighborhood poverty and racial differences in ESRD incidence. J Am Soc Nephrol. 2008;19 (2):356-64.

27. Greer RC, Cooper LA, Crews DC, Powe NR, Boulware LE. Quality of patient-physician discussions about CKD in primary care: A crosssectional study. Am J Kidney Dis. 2010 [Epub ahead of print]

28. Plantinga LC, Tuot DS, Powe NR. Awareness of chronic kidney disease among patients and providers. Adv Chronic Kidney Dis. 17(3):22536.

29. Diamantidis CJ, Powe NR, Jaar BG, Greer RC, Troll MU, Boulware LE. Primary care-specialist collaboration in the care of patients with chronic kidney disease. Clin J Am Soc Nephrol. 2011 [Epub ahead of print]

30. Greer RC, Powe NR, Jaar BG, Troll MU, Boulware LE. Effect of primary care physicians' use of estimated glomerular filtration rate on the timing of their subspecialty referral decisions. BMC Nephrol. 2011;12(1):1. [Epub ahead of print]

31. Saran R, Hedgeman E, Plantinga L, et al. Establishing a national chronic kidney disease surveillance system for the United States. Clin J Am Soc Nephrol. 5(1):152-61. 